\title{
Tetrandrine alleviates symptoms of rheumatoid arthritis in rats by regulating the expression of cyclooxygenase- 2 and inflammatory factors
}

\author{
XIANG LI ${ }^{1}$, ZHONGXIU WU ${ }^{1}$, BIN HE$^{1}$ and WEI ZHONG ${ }^{2}$ \\ ${ }^{1}$ Department of Pharmacy, ${ }^{2}$ Cadre Ward, Zaozhuang Municipal Hospital, Zaozhuang, Shandong 277101, P.R. China
}

Received April 8, 2016; Accepted March 17, 2017

DOI: $10.3892 /$ etm.2018.6498

\begin{abstract}
The present study aimed to construct a rat model of rheumatoid arthritis (RA) to evaluate changes in pathology, the expression of inflammatory factors and regulation of signaling pathways. The protective effect of tetrandrine (Tet) on tissue lesions induced by RA was also investigated. A total of 60 Wistar rats (100-200 g) were randomly divided into six groups ( $\mathrm{n}=10$ per group), namely a blank (NC) group, model group, methotrexate (MTX) group (3 $\mathrm{mg} / \mathrm{kg}$ body weight), high-dose Tet group ( $31.25 \mathrm{mg} / \mathrm{kg}$ body weight), medium-dose Tet group (18.75 mg/kg body weight) and low-dose Tet group (6.25 mg/kg body weight). A rat model of RA was induced via injection of $0.1 \mathrm{ml}$ complete Freund's adjuvant into the right rear toe. Toe swelling rate, arthritis index and immune organ index were calculated. In addition, cyclooxygenase (COX)-2 expression at the mRNA and protein level in the peripheral blood mononuclear cells (PBMCs) of rats were determined by reverse transcription-quantitative polymerase chain reaction and western blot analysis, respectively. Serum concentrations of inflammatory factors were measured using enzyme-linked immunosorbent assays. It was observed that treatment with Tet alleviated the severity of rear toe swelling associated with RA in rats. Furthermore, Tet exerted anti-inflammatory and immunosuppressive effects in the rat model of RA. Tet also reduced the expression of COX-2 in PBMCs and lowered the concentrations of inflammatory factors in the serum of RA rats. The present data indicate that Tet may exert pharmacological effects in the treatment of RA. The mechanism of action of Tet may be associated with the regulation of inflammatory factors and the inhibition of immune organs.
\end{abstract}

Correspondence to: Dr Wei Zhong, Cadre Ward, Zaozhuang Municipal Hospital, 41 Middle Longtou Road, Zaozhuang, Shandong 277101, P.R. China

E-mail: gio567@163.com

Key words: rheumatoid arthritis, complete Freund's adjuvant, tetrandrine, cyclooxygenase-2, inflammatory factors

\section{Introduction}

Rheumatoid arthritis (RA) is a systemic autoimmune disease characterized by symmetrical arthritis, with a morbidity rate among the highest of all autoimmune connective tissue diseases $(1,2)$. The average global incidence of RA is $0.5-1 \%$, whereas in China, the incidence rate reaches $0.32-0.36 \%$ (3). Globally, the highest incidence rates of RA are observed in individuals aged between 40 and 60 years, and the number of female patients with RA is 2- to 3-fold higher than that of male RA patients (4). RA mainly affects synovial joints, and also affects tunica serosa, the heart, lungs, blood vessels, nerves and eyes (5). It is accepted that RA is caused by pathological changes in humoral and cellular immunity (6). The pathogenesis of RA includes synovial lining cell hyperplasia, interstitial inflammatory cell infiltration, angiogenesis, and destruction of cartilage and bone tissues (7). Clinically, RA is mainly treated with drugs such as nonsteroidal anti-inflammatory drugs, disease-modifying anti-rheumatic drugs, glucocorticoids, biological agents and botanical drugs (8-10).

Tetrandrine (Tet), typically administered as an oral tablet, is a bisbenzylisoquinoline calcium antagonist that acts to reduce total peripheral vascular resistance and blood pressure (11). Tet also increases cardiac output and exerts muscle relaxant, antipyretic, analgesic and anti-inflammatory effects, and may inhibit cell proliferation and induce apoptosis $(12,13)$. In addition, Tet tablets may be used for the treatment of simple silicosis, anthracosilicosis, mild hypertension, rheumatalgia, arthralgia and neuralgia (14-16). However, it is not clear whether Tet is effective in the treatment of patients with RA and the mechanism of action of Tet on RA remains unknown. In the present study, a rat model of RA was used to investigate the index scores and expression of relative factors such as interleukin (IL)-6, IL-1 $\beta$, and tumor necrosis factor (TNF)- $\alpha$ in the blood, as well as the effects of the Tet tablet on RA.

\section{Materials and methods}

Animals. A total of 60 Wistar rats (100-200 g; sex ratio, 1:1; mean age, 5-7 weeks) were purchased from the Teng Xin Experimental Animals Company (Chongqing, China). The rats were raised in an environment at $24 \pm 2^{\circ} \mathrm{C}$ with $55 \pm 5 \%$ humidity and a $12 \mathrm{~h}$ light/dark cycle. All rats had free access to food and water. They were randomly divided into the following six 
groups ( $\mathrm{n}=10$ per group): Blank (negative control, NC), RA model, methotrexate (MTX; $3 \mathrm{mg} / \mathrm{kg}$ body weight), high-dose Tet $(31.25 \mathrm{mg} / \mathrm{kg}$ body weight), medium-dose Tet $(18.75 \mathrm{mg} / \mathrm{kg}$ body weight) and low-dose Tet $(6.25 \mathrm{mg} / \mathrm{kg}$ body weight). According to previous methods (17), all rat groups excluding the blank group were injected subcutaneously with $0.1 \mathrm{ml}$ complete Freund's adjuvant (F5881; Sigma-Aldrich; Merck $\mathrm{KGaA}$, Darmstadt, Germany) into the right rear toe to induce inflammation. On day 2 following adjuvant administration, intragastric drug treatments were initiated. The MTX group received intragastric administration of MTX (2.5 mg/tablet once every 3 days; 20150403; Shanghai Xinyi Pharmaceutical Co., Ltd., Shanghai, China) while the Tet groups received intragastric administrations of different concentrations of Tet (20 mg/tablet; H20063332; Beihai Yangguang Pharmaceutical Company Ltd., Beihai, China) at 11 a.m. every day. The blank group received saline alone (daily). All animal experiments were conducted according to the ethical guidelines of Zaozhuang Municipal Hospital (Zaozhuang, China).

Right toe swelling test. Prior to establishment of the RA model, the initial volume of the right rear toe was determined using a swelling measuring instrument (PV-200; Chengdu Techman Software Co., Ltd., Chengdu, China) according to a previously published method (18). Following injection of complete Freund's adjuvant, the volume of the right rear toe was measured once a week. The toe swelling rate was calculated according to the following formula: (Current volume - volume before experiments)/volume before experiment x100\%.

Arthritis index. The extent of arthritis in rats was scored every three days following injection with complete Freund's adjuvant. Arthritis index was determined according to the degree and area of erythema and the joint swelling and deformation status of the rear toe after immunization (19). Scoring was as follows: 0 , rats with normal joint status; 1 , rats with mild erythema and swelling at the rear ankle; 2 , rats with erythema and swelling at the rear ankle joint and tarsal; 3, rats with erythema and moderate swelling from the ankle to metatarsal or metacarpal joint; and 4, rats with severe swelling and erythema from the ankle to metatarsal.

Immune organ index. A primary function of the thymus is to produce T lymphocytes and secrete thymic hormone, and thus the thymus is principally involved in cellular immunity. High levels of lymphocytes and macrophages are present in the spleen, though there is a greater proportion of B lymphocytes present (20). Therefore, the spleen is more closely associated with humoral immunity. Indices of the thymus or spleen are expressed as the weight of the thymus or spleen (mg) per $10 \mathrm{~g}$ body weight. Thymus and spleen indices are dependent on the proliferation of lymphocytes and reflect immune function. On day 28 following adjuvant administration, all rats were sacrificed by decapitation and the spleen and thymus were removed and wet-weighed to calculate indices of the thymus spleen. Indices of the thymus or spleen were calculated as follows: Weight of thymus or spleen (mg)/body weight $(\mathrm{g}) \times 10^{3}$.

Reverse transcription-quantitative polymerase chain reaction $(R T-q P C R)$. On day 28, rats were sacrificed and blood was collected from the abdominal aorta. Peripheral blood mononuclear cells (PBMCs) were isolated from the blood according to the manufacturer's protocol (TBD2011RAT; Haoyang Biological Manufacture Co., Ltd., Tianjin, China) and lysed using TRIzol reagent (10606ES60; Yeasen Corp., Shanghai, China). Total RNA (30 $\mu \mathrm{l})$ was extracted using the phenol chloroform method according to the manufacturer's protocol (RP2401; BioTeke Corporation, Beijing, China). The purity of RNA was determined using ultraviolet spectrophotometry (Nanodrop ND1000; Thermo Scientific, Waltham, MA, USA) according to the ratio of absorbance (A) at 260 and $280 \mathrm{~nm}$ (A260/A280 ratio) following a previously published method (21). cDNA was subsequently obtained by reverse transcription using a TIANScript II cDNA Kit (KR107; Tiangen Biotech Co., Ltd., Beijing, China) from $1 \mu \mathrm{g}$ RNA and stored at $-20^{\circ} \mathrm{C}$. For qPCR, the following primers were used: Cyclooxygenase (COX)-2, forward 5'-CAGCCATAC AGCAAATCCTTG-3' and reverse 5'-CAAATGTGATCT GGATGTCAAC-3'; and $\beta$-actin, forward 5'-CACCAGGGC GTGATGGT-3' and reverse 5'-CTCAAACATGATCTGGGT CAT-3'. The qPCR reaction system $(20 \mu \mathrm{l})$ contained $10 \mu \mathrm{l}$ SYB-RGreen qPCR-Mix, $0.5 \mu 1$ upstream primers, $0.5 \mu 1$

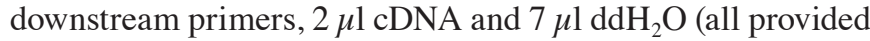
in the SuperReal PreMix SYBR-Green kit; FP204, Tiangen Biotech Co., Ltd.). qPCR was performed using an iCycler iQ5 real-time PCR detection system (Bio-Rad Laboratories, Inc., Hercules, CA, USA) and the PCR protocol was as follows: Initial denaturation at $95^{\circ} \mathrm{C}$ for $30 \mathrm{sec}$, followed by 40 cycles of denaturation at $95^{\circ} \mathrm{C}$ for $5 \mathrm{sec}$ and annealing at $60^{\circ} \mathrm{C}$ for $34 \mathrm{sec}$. The $2^{-\Delta \Delta \mathrm{Cq}}$ method (22) was used to calculate the relative expression of COX-2 against the expression of $\beta$-actin. Each sample was tested in triplicate.

Western blotting. PBMCs were trypsinized and the resulting lysates collected. Pre-cooled radioimmunoprecipitation assay lysis buffer (600 $\mu \mathrm{l}$; $50 \mathrm{mM}$ Tris-base, $1 \mathrm{mM}$ EDTA, $150 \mathrm{mM}$ $\mathrm{NaCl}, 0.1 \%$ SDS, $1 \%$ TritonX-100 and $1 \%$ sodium deoxycholate; Beyotime Institute of Biotechnology, Haimen, China) was then added to the samples (final volume, $620 \mu 1$ ). Following lysis for $50 \mathrm{~min}$ on ice, the mixture was centrifuged at $12,000 \mathrm{x}$ g at $4^{\circ} \mathrm{C}$ for $5 \mathrm{~min}$. The protein concentration of the resulting supernatant was determined using a bicinchoninic acid protein concentration determination kit (RTP7102; Real-Times Biotechnology Co., Ltd., Beijing, China). Protein samples $(20 \mu \mathrm{g})$ were then mixed with SDS loading buffer prior to denaturation in a boiling water bath for $5 \mathrm{~min}$. Protein samples $(50 \mu \mathrm{g})$ were then subjected to $10 \%$ SDS-polyacrylamide gel electrophoresis. Resolved proteins were transferred to polyvinylidene difluoride membranes on ice $(100 \mathrm{~V} ; 2 \mathrm{~h})$ and blocked with $5 \%$ skimmed milk at room temperature for $1 \mathrm{~h}$. Membranes were then incubated with rabbit anti-mouse COX-2 polyclonal primary antibody (1:1,000; ab52237; Abcam, Cambridge, UK) and rabbit anti-mouse $\beta$-actin primary antibody $(1: 5,000$; ab129348; Abcam) at $4^{\circ} \mathrm{C}$ overnight. After $3 \times 15$ min washes with PBST, membranes were incubated with goat anti-rabbit horseradish peroxidase-conjugated secondary antibody (1:3,000; ab6721; Abcam) for $1 \mathrm{~h}$ at room temperature, before $3 \times 15$ min washes with PBST. Membranes were developed for imaging using an enhanced chemiluminescence detection kit (Sigma-Aldrich; Merck KGaA). Image Lab 3.0 software 
(Bio-Rad Laboratories, Inc.) was used to detect and analyze imaging signals. The relative content of COX-2 protein was expressed as a $\mathrm{COX}-2 / \beta$-actin ratio.

Enzyme-linked immunosorbent assay (ELISA). Blood samples were centrifuged at $1,200 \mathrm{x}$ g for 10 min under room temperature to isolate serum. Levels of interleukin IL-6, IL-1 and TNF- $\alpha$ were measured using ELISA kits (ERC003.96, ERC007.96 and ERC102a.96, respectively; Neobioscience, Shenzhen, China), according to the manufacturer's protocol. Absorbance at $450 \mathrm{~nm}$ was measured using a microplate reader (DG5033A; Nanjing Huadong Electronics Group Co., Ltd., Nanjing, China) within $15 \mathrm{~min}$ of terminating the reactions.

Statistical analysis. Results were analyzed using SPSS 18.0 software (SPSS, Inc., Chicago, IL, USA). Data were expressed as the mean \pm standard deviation. Multiple sets of measurement data were initially compared using one-way analysis of variance to test for normality. For data exhibiting homogeneity of variance, data were analyzed using Least Significant Difference and Student-Newman-Keuls methods. For data exhibiting heterogeneity of variance, Tamhane's T2 or Dunnett's T3 methods were used. Each assay was repeated a minimum of 3 times. $\mathrm{P}<0.05$ was considered to indicate a statistically significant difference.

\section{Results}

Tet treatment alleviates the severity of rear toe swelling in a rat model of $R A$. To determine the effect of Tet on toe swelling in RA rats, a swelling measuring instrument was used. Following injection of complete Freund's adjuvant, visual observation showed that right toe swelling was apparent by $24 \mathrm{~h}$ in rats of the model group, and became aggravated on day 7. On day 21 , the swelling became more severe, and the right rear toe exhibited partial loss of movement. On day 28 , the majority of movement in the right rear toe had been lost. By contrast, swelling was alleviated in rats in the high dose group treated with Tet on day 7. Quantification showed that toe swelling rates in the MTX and high dose groups were significantly lower than that in model group on day 7, and those in the MTX and all dose groups were significantly lower than the model group on days 14,21 and 28 ( $\mathrm{P}<0.05$ compared with model group; Fig. 1). These data suggest that treatment with Tet may alleviate the severity of RA-induced rear toe swelling in rats.

Tet exerts anti-inflammatory effects in a rat model of $R A$. To determine the effect of Tet on the extent of arthritis in rats, an arthritis index was calculated. It was observed that the arthritis index in rats of the model group gradually increased within the first 18 days, reaching a peak on day 18 , before decreasing between days 18 and 28. Following treatment, the arthritis indices of rats in the MTX, high dose and medium dose groups were significantly lower than that of rats in model group from day 12 to day 28 (all $\mathrm{P}<0.05$ compared with model group; Fig. 2). These results indicate that Tet may exert anti-inflammatory effects in rats with RA.

Tet exerts immunosuppressive effects in a rat model of $R A$. To evaluate the effect of Tet on immune organ indices, weights

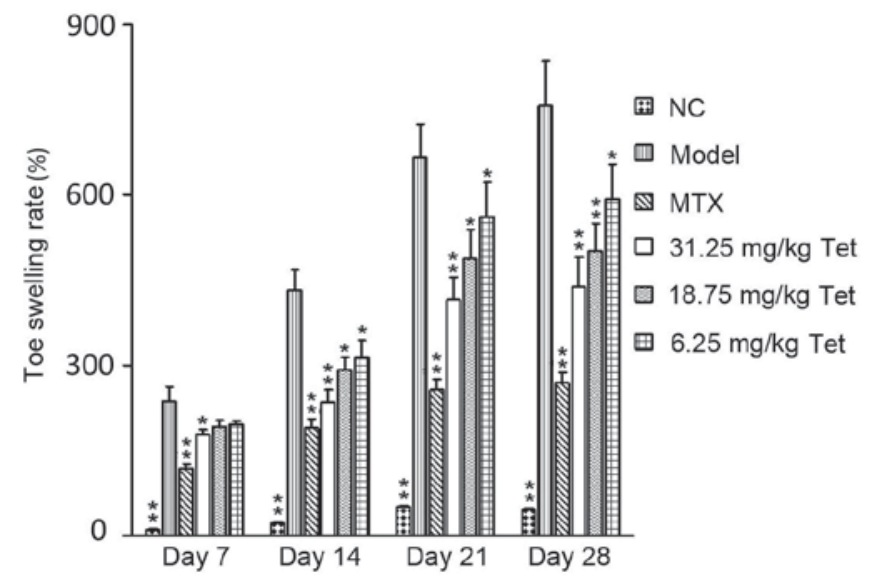

Figure 1. Effect of Tet on the rate of toe swelling in RA rats. The MTX group received intragastric administration of methotrexate $(3 \mathrm{mg} / \mathrm{kg}$ body weight) twice a week, while the Tet groups received daily intragastric administration of different concentrations of Tet $(31.25,18.75$ or $6.25 \mathrm{mg} / \mathrm{kg}$ body weight). The $\mathrm{NC}$ group received normal saline alone once a day. Prior to model establishment, the initial volume of the right rear toe was determined using a swelling measuring instrument. Following injection of complete Freund's adjuvant, the volume of the right rear toe was measured once a week. Toe swelling rate was calculated as follows: Toe swelling rate $=($ Current volume-volume before experiments $) /$ volume before experiment $\mathrm{x} 100 \%$. Data are expressed as the mean + standard deviation ( $\mathrm{n}=10$ per group). ${ }^{*} \mathrm{P}<0.05$ and ${ }^{* *} \mathrm{P}<0.01$ vs. $\mathrm{RA}$ model group. RA, rheumatoid arthritis; Tet, tetrandrine; MTX, methotrexate; NC, blank negative control.

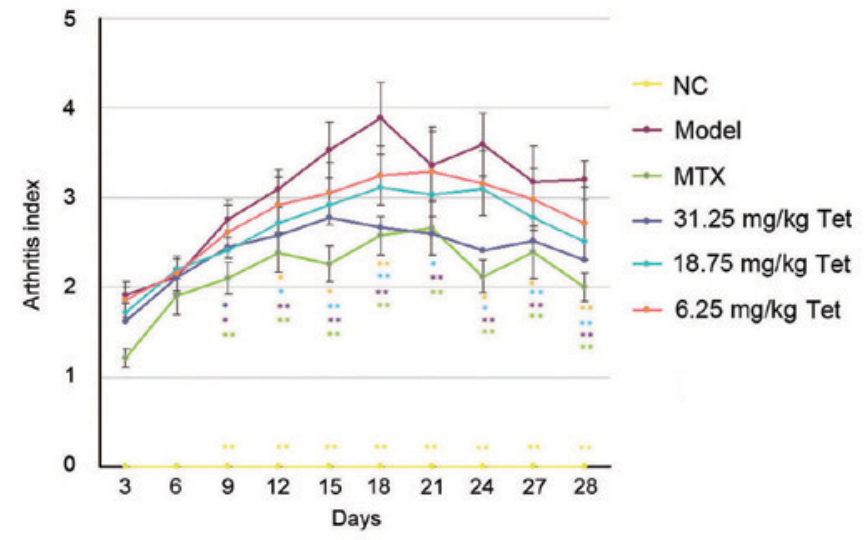

Figure 2. Effect of Tet on the arthritis index of RA rats. The extent of arthritis in RA rats was measured every three days following an injection of complete Freund's adjuvant into the right rear toe. The arthritis index was calculated according to the degree and area of erythema and the joint swelling and deformation status of the rear toe following immunization. Data are expressed as the mean \pm standard deviation ( $\mathrm{n}=10$ per group). ${ }^{*} \mathrm{P}<0.05$ and ${ }^{* *} \mathrm{P}<0.01$ vs. $\mathrm{RA}$ model group. RA, rheumatoid arthritis; Tet, tetrandrine; MTX, methotrexate; $\mathrm{NC}$, blank negative control.

of the spleen and thymus following the experimental period (28 days) were used to determine thymus and spleen indices. The data indicated that treatment with MTX or Tet (low, medium and high dose groups) significantly decreased the thymus index (for MTX group and all Tet dose groups, $\mathrm{P}<0.05$ compared with model group; Fig. 3A) and spleen index (for MTX group and all Tet dose groups, $\mathrm{P}<0.05$ compared with model group; Fig. 3B). Thus, Tet may exert immunosuppressive effects in a rat model of RA. 
Tet reduces COX-2 expression in the PBMCs of RA rats. To determine the effect of Tet on COX-2 expression at the mRNA and protein level in the PBMCs of rats, RT-qPCR and western blotting were performed, respectively. It was observed that COX-2 was significantly upregulated at the mRNA and protein level in the PBMCs of the model group, relative to the blank (NC) group (both $\mathrm{P}<0.01$ ). Following treatment, levels of COX-2 mRNA and protein in MTX group and all Tet dose groups were significantly reduced compared with the model group (for MTX and Tet dose groups, $\mathrm{P}<0.05$ compared with model group; Fig. 4). These results indicate that Tet may downregulate the expression of COX-2 in the PBMCs of RA rats.

Tet reduces the concentration of inflammatory factors in the serum of RA rats. Using ELISA, levels of inflammatory factors in the serum of RA rats were measured. The data indicated that levels of of IL-1 $\beta(\mathrm{P}<0.01)$, IL-6 $(\mathrm{P}<0.01)$ and TNF- $\alpha(\mathrm{P}<0.05)$ in the model group were significantly higher than those in the NC group. In turn, treatment with MTX or Tet (low, medium and high doses) significantly reduced levels of inflammatory factors in the serum compared with the model group (MTX group and all Tet dose groups, $\mathrm{P}<0.05$ compared with model group; Fig. 5). Therefore, Tet may lower the concentration of inflammatory factors in the serum of RA rats.

\section{Discussion}

Tet is a bisbenzylisoquinoline alkaloid extracted from the root of Stephaniae tetrandrae Radix, a plant belonging to the menispermaceae family. Tet comprises $\sim 1 \%$ of the root of Stephaniae tetrandrae Radix (23), and has been documented to have numerous pharmacological effects (24), including anti-myocardial ischemia activities, inhibitory effects on platelet aggregation (25) and spasmolytic (26), anti-tumor (27), analgesic, anti-inflammatory (28), anti-ulcer and hepatoprotective effects $(29,30)$. Tet has also been implicated in the regulation of immunity (31), hypoxia tolerance (14) and suppression of rheumatalgia, arthralgia and neuralgia $(32,33)$.

RA is pathological change specific to the joints that is characterized by hyperplasia of synovial tissues, vascular exclusion and the formation of granulation tissues $(34,35)$. In the pathogenesis of RA, inflammation that originates in the synovial membrane spreads to cartilage and bone tissues, leading to destruction of the joint structure. Inflammatory mechanisms also induce angiogenesis, which further accelerates joint damage and leads to joint deformity, rigidity and loss of function (36). RA is a chronic process and patients typically experience episodes of alternating occurrence and alleviation. Although individual cases differ, the morbidity rate of RA may reach $60-70 \%$ (37). Therefore, studies providing insight into the underlying mechanism of RA are warranted to identify novel therapeutic drugs. To date, it has been documented that a number of mRNA and microRNA molecules are involved in the pathogenesis of RA (38), and numerous inflammatory cytokines, including TNF- $\alpha$ and IL-1, may participate in the damaging inflammatory responses observed in RA $(39,40)$.

In the present study, rate of toe swelling and an arthritis index were measured, as indicators of the potential therapeutic effects of Tet on RA. It was observed that treatment

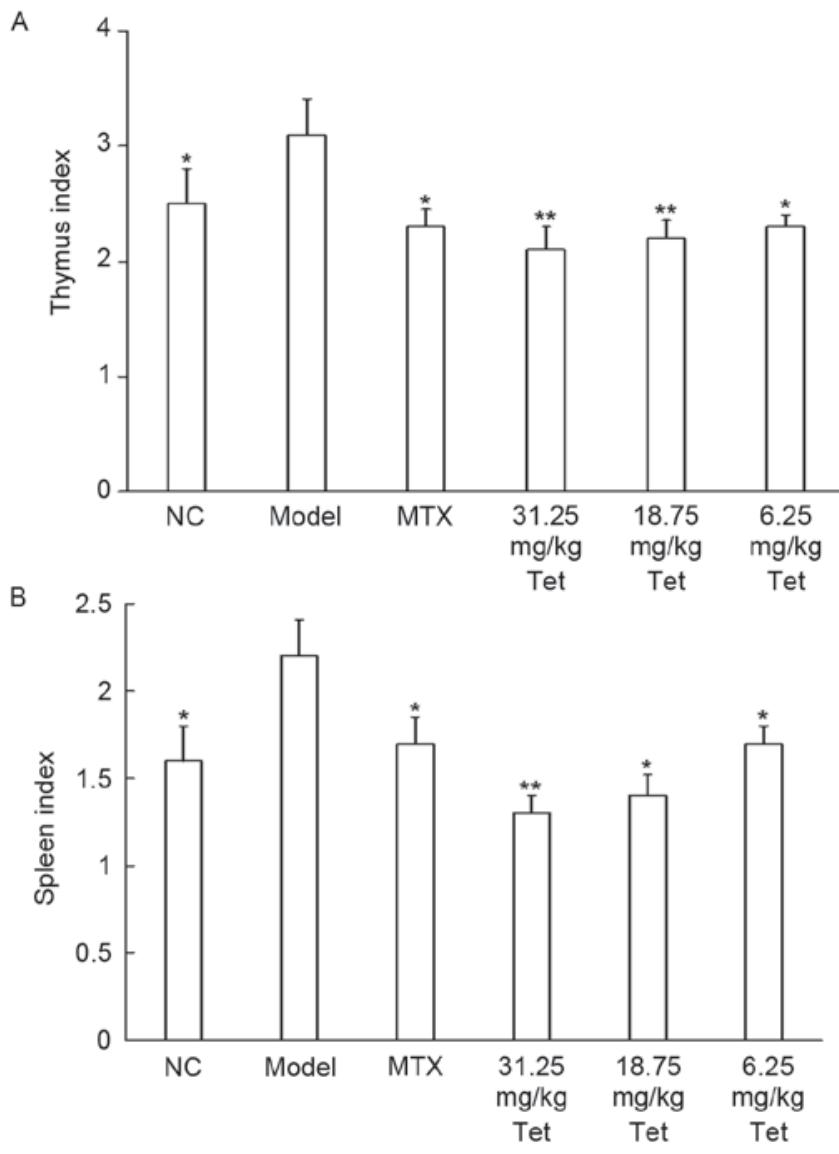

Figure 3. Effect of Tet on immune organ indices. After the 28-day experimental period, weights of the spleen and thymus were used to calculate the (A) thymus index and (B) spleen index. Thymus and spleen indices were calculated as follows: Weight of thymus or spleen $(\mathrm{mg}) /$ body weight $(\mathrm{g})$ $\mathrm{x} 10^{3}$. Data are expressed as the mean + standard deviation ( $\mathrm{n}=10$ per group). ${ }^{*} \mathrm{P}<0.05$ and $^{* *} \mathrm{P}<0.01$ vs. model group. Tet, tetrandrine; MTX, methotrexate; $\mathrm{NC}$, blank negative control.

with Tet alleviated swelling of the right rear toe of the rats. In particular, the effects of high-dose Tet $(31.25 \mathrm{mg} / \mathrm{kg}$ body weight) were similar to that of MTX. As an approved drug for RA, MTX is more effective in the treatment of adjuvant-induced arthritis models compared with Tet (41). However, MTX may suppress the formation of bone marrow and affect liver and kidney functions. By contrast, Tet does not exert these side effects. The present study investigated the effects of Tet to compare the effects of Tet and MTX and to determine whether future studies into the combined use of both drugs are warranted.

Arthritis index measurements were comparable to those of the toe swelling assay. However, there was a discrepancy between the immunosuppressive effects of Tet and changes in the toe swelling rate and arthritis index, possibly due to the effects of Tet on lymphocyte activity. Nonetheless, thymus and spleen indices may serve as rough estimates of immune function.

The thymus and spleen are major immune organs in the body, with the thymus functioning as a central immune organ and the spleen as a peripheral immune organ. Changes in the thymus and spleen indices are considered to reflect the overall immune function of the body $(42,43)$. The present study demonstrated that Tet decreased indices of the thymus 

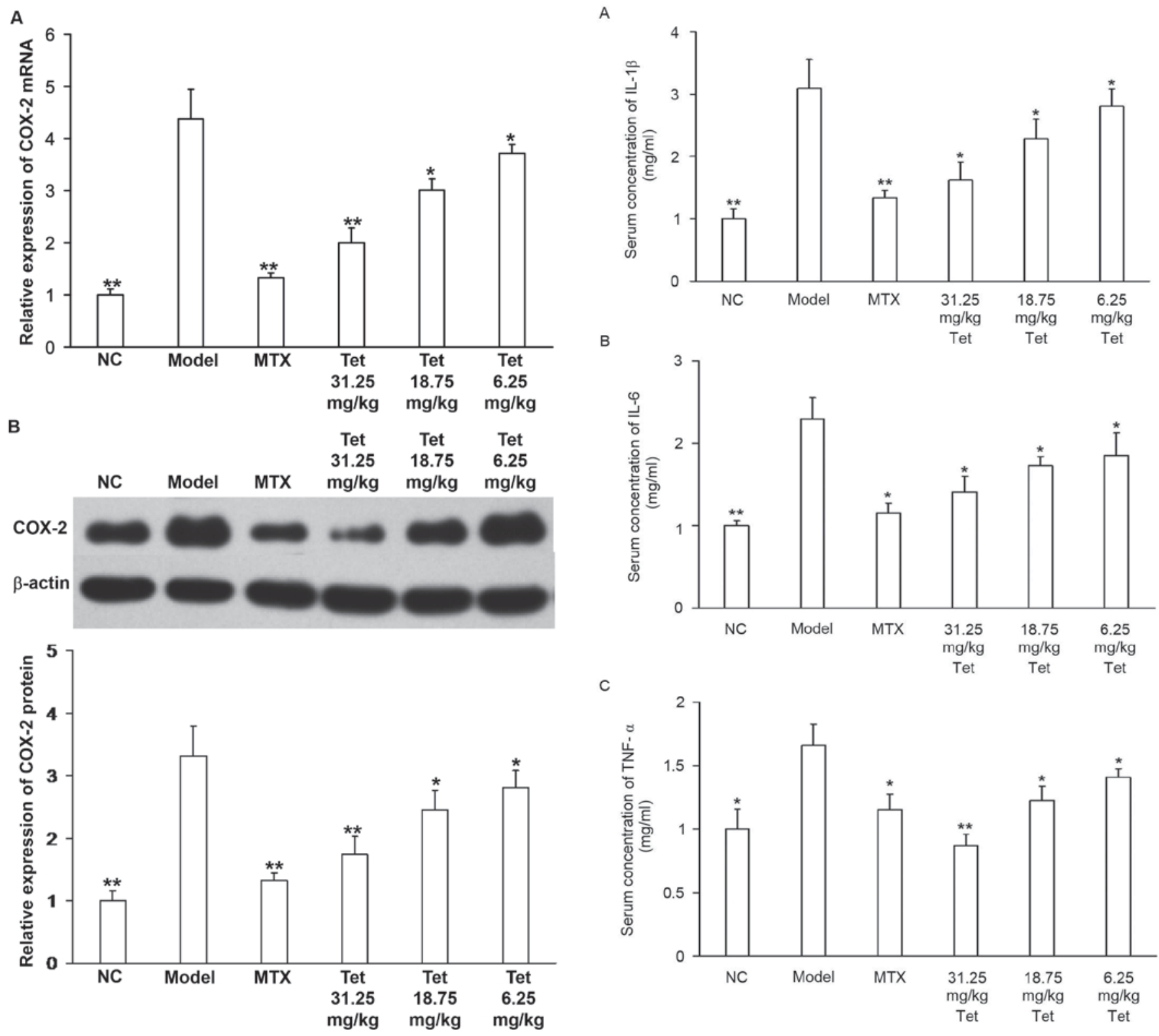

Figure 4. Effect of Tet on COX-2 expression in the peripheral blood mononuclear cells of RA rats. (A) Expression of COX-2 mRNA determined using reverse transcription-quantitative polymerase chain reaction. (B) Expression of COX-2 protein measured by western blotting. Representative western blots are shown. Values of COX-2 protein expression are relative to that of $\beta$-actin. Data are expressed as the mean + standard deviation ( $n=10$ per group). ${ }^{*} \mathrm{P}<0.05$ and ${ }^{* *} \mathrm{P}<0.01$ vs. model group. Tet, tetrandrine; COX-2, cycloxygenase-2; MTX, methotrexate; NC, blank negative control.

and spleen, suggesting that Tet may inhibit the functions of the thymus and spleen in RA rats.

COX-2 is a major inflammatory enzyme that has a rate-limiting role in the synthesis of prostaglandin (44). COX-2 also converts arachidonic acid into prostaglandin endoperoxides, which are subsequently converted to thromboxane A2 and prostaglandin to exert inflammatory effects (45). High expression of COX-2 is considered to be a key sign of inflammation (46). Results of the present study indicated that Tet reduced the expression of COX-2 at the mRNA and protein level in the PBMCs of RA rats, suggesting that Tet may inhibit inflammatory responses in the body. It has also been documented that pro-inflammatory cytokines, including TNF- $\alpha$,

Figure 5. Effect of Tet on the concentration of inflammatory factors in the serum of RA rats. Serum levels of (A) IL-1 $\beta$, (B) IL-6 and (C) TNF- $\alpha$ were measured using ELISA. Data are expressed as the mean + standard deviation ( $\mathrm{n}=10$ per group). ${ }^{*} \mathrm{P}<0.05$ and ${ }^{* *} \mathrm{P}<0.01$ vs. model group. Tet, tetrandrine; IL, interleukin; TNF, tumor necrosis factor; MTX, methotrexate; NC, blank negative control.

IL-1 $\beta$ and IL-6, are upregulated in RA foci (47). Cytokines may be key etiological factors in RA that affect the destruction of joint and articular cartilage in patients with RA (48). The current study demonstrated that Tet treatment significantly reduced the concentrations of TNF- $\alpha$, IL- $1 \beta$ and IL- 6 in the serum of RA rats, which was consistent with results of the immune organ index and COX-2 expression assays.

A limitation of the present study was the absence of Tand/or B-cell activity assays, and thus these are warranted in future studies. In conclusion, the present study demonstrated that Tet alleviated the pathological manifestations of RA in rats. The underlying mechanisms regarding the effects of Tet may involve suppression of immune organs, downregulation of COX-2 and a reduction in the release of blood inflammatory factors. Compared with MTX, the pharmacological 
effects of Tet were not advantageous. However, as Tet has fewer side effects, studies into the use of Tet within combined or auxiliary drug therapies for the treatment of RA are warranted.

\section{References}

1. Sandoo A, Veldhuijzen van Zanten JJ, Metsios GS, Carroll D and Kitas GD: Vascular function and morphology in rheumatoid arthritis: A systematic review. Rheumatology (Oxford) 50 2125-2139, 2011

2. Thomas E, Symmons DP, Brewster DH, Black RJ and Macfarlane GJ: National study of cause-specific mortality in rheumatoid arthritis, juvenile chronic arthritis, and other rheumatic conditions: A 20 year followup study. J Rheumatol 30: 958-965, 2003.

3. Lu Z and Zhong N: Internal medicine. 7th edition. Beijing: People's Medical Publishing House, pp848, 2008.

4. Koushik S, Joshi N, Nagaraju S, Mahmood S, Mudeenahally K, Padmavathy R, Jegatheesan SK, Mullangi R and Rajagopal S: PAD4: Pathophysiology, current therapeutics and future perspective in rheumatoid arthritis. Expert Opin Ther Targets 21: 433-447, 2017.

5. Worthington J, Barton A and John SL: The epidemiology of rheumatoid arthritis and the use of linkage and association studies to identify disease genes. In: The hereditary basis of rheumatic disease. Rikard Holmdahl (ed). Birkhäuser Basel, Switzerland: 9-28, 2006.

6. Smolen JS, Aletaha D and McInnes IB: Rheumatoid arthritis. Lancet 388: 2023-2038, 2016.

7. Venuturupalli S: Immune mechanisms and novel targets in rheumatoid arthritis. Immunol Allergy Clin North Am 37: 301-313, 2017.

8. Wolfe RM and Ang DC: Biologic therapies for autoimmune and connective tissue diseases. Immunol Allergy Clin North Am 37: 283-299, 2017.

9. Diaper R, Wong E and Metcalfe SA: The implications of biologic therapy for elective foot and ankle surgery in patients with rheumatoid arthritis. Foot (Edinb) 30: 53-58, 2017.

10. Lampropoulos CE, Orfanos P, Manoussakis MN, Tzioufas AG, Moutsopoulos HM and Vlachoyiannopoulos PG: Treat-to-target biologic therapy in patients with rheumatoid arthritis is more efficacious and safe compared to delayed initiation of biologics: A real-world study. Clin Exp Rheumatol 35: 192-200, 2017.

11. Xu XH, Gan YC, Xu GB, Chen T, Zhou H, Tang JF, Gu Y, Xu F, Xie YY, Zhao XY and Xu RZ: Tetrandrine citrate eliminates imatinib-resistant chronic myeloid leukemia cells in vitro and in vivo by inhibiting $\mathrm{Bcr}-\mathrm{Abl} / \beta$-catenin axis. J Zhejiang Univ Sci B 13: 867-874, 2012.

12. He BC, Gao JL, Zhang BQ, Luo Q, Shi Q, Kim SH, Huang E, Gao Y, Yang K, Wagner ER, et al: Tetrandrine inhibits $\mathrm{Wnt} / \beta$-catenin signaling and suppresses tumor growth of human colorectal cancer. Mol Pharmacol 79: 211-219, 2011.

13. Hou Y, Guo T, Wu C and He X: Effect of tetrandrine combined with epirubicin on the growth of human breast carcinoma multidrug resistance cell line. Yakugaku Zasshi 128: 663-666, 2008.

14. Chen Y, Tsai YH and Tseng SH: The potential of tetrandrine as a protective agent for ischemic stroke. Molecules 16: 8020-8032, 2011.

15. Xie W and Du L: Diabetes is an inflammatory disease: Evidence from traditional Chinese medicines. Diabetes Obes Metab 13: 289-301, 2011

16. Idec-Sadkowska I, Andrzejak R, Antonowicz-Juchniewicz J and Kaczmarek-Wdowiak B: Trials of casual treatment of silicosis. Med Pr 57: 271-280, 2006 (In Polish).

17. Perera PK, Peng C, Xue L, Li Y and Han C: Ex vivo and in vivo effect of Chinese herbal pill Yi Shen Juan Bi (YJB) on experimental arthritis. J Ethnopharmacol 134: 171-175, 2011

18. Lin B, Zhang H, Zhao XX, Rahman K, Wang Y, Ma XQ, Zheng CJ, Zhang QY, Han T and Qin LP: Inhibitory effects of the root extract of Litsea cubeba (lour.) pers. on adjuvant arthritis in rats. J Ethnopharmacol 147: 327-334, 2013.

19. Davies NM and Jamali F: COX-2 selective inhibitors cardiac toxicity: Getting to the heart of the matter. J Pharm Pharm Sci 7 : 332-336, 2004.

20. Steiniger B and van der Meide PH: High-dose interferon-gamma alters the distribution of B lymphocytes and macrophages in rat spleen and lymph nodes. Immunology 78: 461-467, 1993.
21. Koshy L, Anju AL, Harikrishnan S, Kutty VR, Jissa VT, Kurikesu I, Jayachandran P, Jayakumaran Nair A, Gangaprasad A, Nair GM and Sudhakaran PR: Evaluating genomic DNA extraction methods from human whole blood using endpoint and real-time PCR assays. Mol Biol Rep 44: 97-108, 2017.

22. Livak KJ and Schmittgen TD: Analysis of relative gene expression data using real-time quantitative PCR and the 2(-Delta Delta C(T)) method. Methods 25: 402-408, 2001

23. Ge S, Cui L and Wang P: Research progress on pharmacological effects of tetrandrine. Chin Traditional Herbal Drugs 31: W004-W006, 2000.

24. Bhagya $\mathrm{N}$ and Chandrashekar KR: Tetrandrine-A molecule of wide bioactivity. Phytochemistry 125: 5-13, 2016.

25. Rao MR: Effects of tetrandrine on cardiac and vascular remodeling. Acta Pharmacol Sin 23: 1075-1085, 2002

26. Li DG, Wang ZR and Lu HM: Pharmacology of tetrandrine and its therapeutic use in digestive diseases. World J Gastroenterol 7: 627-629, 2001.

27. Liu T, Liu X and Li W: Tetrandrine, a Chinese plant-derived alkaloid, is a potential candidate for cancer chemotherapy. Oncotarget 7: 40800-40815, 2016.

28. Xie QM, Tang HF, Chen JQ and Bian RL: Pharmacological actions of tetrandrine in inflammatory pulmonary diseases. Acta Pharmacol Sin 23: 1107-1113, 2002.

29. Hsu YC, Chiu YT, Cheng CC, Wu CF, Lin YL and Huang YT: Antifibrotic effects of tetrandrine on hepatic stellate cells and rats with liver fibrosis. J Gastroenterol Hepatol 22: 99-111, 2007.

30. Chan CM, Chan YW, Lau CH, Lau TW, Lau KM, Lam FC, Che CT, Leung PC, Fung KP, Lau CB and Ho YY: Influence of an anti-diabetic foot ulcer formula and its component herbs on tissue and systemic glucose homeostasis. J Ethnopharmacol 109: 10-20, 2007.

31. Lai JH: Immunomodulatory effects and mechanisms of plant alkaloid tetrandrine in autoimmune diseases. Acta Pharmacol Sin 23: 1093-1101, 2002.

32. Hu GX, Hu Y, Fang DC and Jiang MX: Hemodynamic effects of tetrandrine in conscious rats. Zhongguo Yao Li Xue Bao 8: 325-328, 1987 (In Chinese).

33. Ho LJ and Lai JH: Chinese herbs as immunomodulators and potential disease-modifying antirheumatic drugs in autoimmune disorders. Curr Drug Metab 5: 181-192, 2004

34. Caplazi P, Baca M, Barck K, Carano RA, DeVoss J, Lee WP, Bolon B and Diehl L: Mouse models of rheumatoid arthritis. Vet Pathol 52: 819-826, 2015.

35. Chieng LO, Madhavan K and Vanni S: Pooled data analysis on anterior versus posterior approach for rheumatoid arthritis at the craniovertebral junction. Neurosurg Focus 38: E18, 2015.

36. Olumuyiwa-Akeredolu $\mathrm{OO}$ and Pretorius E: Platelet and red blood cell interactions and their in rheumatoid arthritis. Rheumatol Int 35: 1955-1964, 2015.

37. Kerola AM, Kauppi MJ, Nieminen T, Rantalaiho V, Kautiainen $H$, Kerola T, Virta LJ, Pohjolainen T and Puolakka K: Psychiatric and cardiovascular comorbidities as causes of long-term work disability among individuals with recent-onset rheumatoid arthritis. Scand J Rheumatol 44: 87-92, 2015.

38. Murata K, Yoshitomi H, Furu M, Ishikawa M, Shibuya H, Ito H and Matsuda S: MicroRNA-451 down-regulates neutrophil chemotaxis via p38 MAPK. Arthritis Rheumatol 66: 549-559, 2014.

39. Matsuno H, Yudoh K, Katayama R, Nakazawa F, Uzuki M, Sawai T, Yonezawa T, Saeki Y, Panayi GS, Pitzalis C and Kimura T: The role of TNF-alpha in the pathogenesis of inflammation and joint destruction in rheumatoid arthritis (RA): A study using a human RA/SCID mouse chimera. Rheumatology (Oxford) 41: 329-337, 2002

40. Walker JG, Ahern MJ, Coleman M, Weedon H, Papangelis V, Beroukas D, Roberts-Thomson PJ and Smith MD: Expression of Jak3, STAT1, STAT4, and STAT6 in inflammatory arthritis: Unique Jak3 and STAT4 expression in dendritic cells in seropositive rheumatoid arthritis. Ann Rheum Dis 65: 149-156, 2006.

41. Smolen JS, Agarwal SK, Ilivanova E, Xu XL, Miao Y, Zhuang Y, Nnane I, Radziszewski W, Greenspan A, Beutler A and Baker D: A randomised phase II study evaluating the efficacy and safety of subcutaneously administered ustekinumab and guselkumab in patients with active rheumatoid arthritis despite treatment with methotrexate. Ann Rheum Dis 76: 831-839, 2017.

42. Serag El-Dien MM, Abdou AG, Asaad NY, Abd El-Wahed MM and Kora MA: Intratumoral FOXP3+ regulatory $\mathrm{T}$ cells in diffuse large B-cell lymphoma. Appl Immunohistochem Mol Morphol: Feb 9, 2016 (Epub ahead of print). 
43. Liu JY, Feng CP, Li X, Chang MC, Meng JL and Xu LJ: Immunomodulatory and antioxidative activity of Cordyceps militaris polysaccharides in mice. Int J Biol Macromol 86 : 594-598, 2016

44. Yu L, Yang B, Wang J, Zhao L, Luo W, Jiang Q and Yang J: Time course change of COX2-PGI2/TXA2 following global cerebral ischemia reperfusion injury in rat hippocampus. Behav Brain Funct 10: 42, 2014.

45. Yoon HY, Lee EG, Lee H, Cho IJ, Choi YJ, Sung MS, Yoo HG and Yoo WH: Kaempferol inhibits IL-1 $\beta$-induced proliferation of rheumatoid arthritis synovial fibroblasts and the production of COX-2, PGE2 and MMPs. Int J Mol Med 32: 971-977, 2013.
46. Yorifuji M, Sawaji Y, Endo K, Kosaka T and Yamamoto K: Limited efficacy of COX-2 inhibitors on nerve growth factor and metalloproteinases expressions in human synovial fibroblasts. J Orthop Sci 21: 381-388, 2016.

47. Choy EH and Panayi GS: Cytokine pathways and joint inflammation in rheumatoid arthritis. N Engl J Med 344: 907-916, 2001.

48. Choi EM and Hwang JK: Effects of methanolic extract and fractions from Litsea cubeba bark on the production of inflammatory mediators in RAW264.7 cells. Fitoterapia 75: 141-148, 2004. 